\title{
Gut microbial imbalance and neurodegenerative proteinopathies: from molecular mechanisms to prospects of clinical applications
}

\author{
Paula Alonso-García ${ }^{1}$, Rebeca Martín $^{2+}{ }^{*}$ (C) Eva Martínez-Pinilla ${ }^{1,3,4+^{*}}$ (1) \\ ${ }^{1}$ Department of Morphology and Cell Biology, Faculty of Medicine, University of Oviedo, 33006 Oviedo, Spain \\ ${ }^{2}$ Micalis Institute, AgroParisTech, INRAE, Université Paris-Saclay, 78350 Jouy-en-Josas, France \\ ${ }^{3}$ Instituto de Neurociencias del Principado de Asturias (INEUROPA), 33003 Oviedo, Spain \\ ${ }^{4}$ Instituto de Investigación Sanitaria del Principado de Asturias (ISPA), 33011 Oviedo, Spain
}

${ }^{+}$These authors contributed equally to this work.

*Correspondence: Eva Martínez Pinilla, Department of Morphology and Cell Biology, University of Oviedo, Julián Clavería s/n, 33006, Asturias, Spain. martinezeva@uniovi.es; Rebeca Martín, Micalis Institute, AgroParisTech, INRAE, Université ParisSaclay, 78350 Jouy-en-Josas, France. rebeca.martin-rosique@inrae.fr

Academic Editor: Rafael Franco, Universitat de Barcelona, Spain

Received: April 2, 2021 Accepted: May 11, 2021 Published: August 5, 2021

Cite this article: Alonso-García P, Martín R, Martínez-Pinilla E. Gut microbial imbalance and neurodegenerative proteinopathies: from molecular mechanisms to prospects of clinical applications. Explor Neuroprot Ther. 2021;1:33-54. https://doi. org/10.37349/ent.2021.00005

\begin{abstract}
The pathogenic basis behind some of the most prevalent neurodegenerative diseases in advanced societies, known as proteinopathies, deals with alterations in protein homeostasis. Despite the broad diversity of clinical symptoms, they share a remarkably common feature that is the serious neuronal loss in several disease-specific brain regions due to the presence of toxic aggregations of misfolded proteins. So far, research efforts have been insufficient to decipher the exact molecular mechanisms that trigger the conformational change from a functional healthy protein to its pathological version. This is a sine qua non condition to progress in developing new approaches and treatments for these diseases for which there is no cure. Currently, it is well accepted that perturbations in gut microbiota composition negatively impact a wide range of brain processes via the gut-brain axis which increases host susceptibility to neurodegenerative disorders. In this context, modulate the microbial ecosystem colonizing the gastrointestinal tract may be a promising therapeutic approach in the management of proteinopathies. This review aims to provide an updated view of the role that gut microbiota poses in the pathogenesis of Parkinson's disease, Alzheimer's disease and Huntington's disease, the most common neurodegenerative proteinopathies, and of the possibility of translating this knowledge into effective and safe clinical microbiota-based interventions, especially those designed to afford neuroprotection.
\end{abstract}

\section{Keywords}

Alzheimer's disease, Parkinson's disease, Huntington's disease, gut microbiota, protein aggregation, dysbiosis, gut-brain axis, probiotics, life biotherapeutics 


\section{Introduction}

Neurodegenerative diseases (ND) have become an important public health concern in last decades affecting millions of people throughout the world, particularly in developed countries. Their associated direct and indirect socioeconomic impact is of paramount relevance and it is expected to rise at $\$ 1$ trillion by 2030 [1]. Despite significant advances in recent years, the understanding of pathological mechanisms of different ND remains unknown and the development of disease-modifying therapeutic interventions has not been as advanced as had been hoped. Nowadays, there is still no cure for the most frequent ND and the medical therapies only provide symptomatic relief at best. Under this discouraging scenario, a great and urgent effort is needed to better comprehend the etiopathology of these diseases and to identify early biological markers that translate into new curative therapies.

Some of the most prevalent ND in advanced societies as Alzheimer's disease (AD), Parkinson's disease (PD), Lewy body dementia (LBD), Huntington's disease (HD) or amyotrophic lateral sclerosis (ALS) belong to proteinopathies family. This term encompasses any of the disorders characterized by protein deposits within neurons, or in the brain parenchyma, which ultimately result in cellular dysfunction, impaired synaptic function and clinical abnormalities [1, 2]. Although the disease-specific brain areas affected are different, they share typical clinical phenotypes that cover behavioural and cognitive changes, deficits in primary motor and/or executive and language functions, and premature death. As a general rule, these proteins with diverse physiological functions in healthy brains suffer a conformational change owing to their physical and chemical properties (i.e., from monomers to aberrant oligomers) that lead to neurotoxic high order aggregates [3]. Pathological deposits formed by these aggregation-prone proteins were first identified in PD. In fact, this pathology is characterized by the presence of $\alpha$-synuclein $(\alpha$-syn) cytoplasmic inclusions in the so-called Lewy bodies in the substantia nigra (SN) and surrounding brain regions. In $\mathrm{AD}$, up to two types of abnormal protein deposits, the pathological hallmarks of the disease, can be identified; the amyloid plaques result from the extracellular accumulation of $\beta$-amyloid peptide (A $\beta$ ), and the neurofibrillary tangles composed of anomalous filaments of hyperphosphorylated microtubuleassociated protein tau inside neurons. Other less well-known proteinopathy is HD where impaired folding of huntingtin (HTT) protein leads to toxic cytoplasmic and nuclear aggregates in inhibitory neurons in the striatum of the basal ganglia [2]. Occasionally, even different types of protein deposits may find together in the same disease [4]. The still pending questions are: why these proteins accumulate? or what factors trigger the protein aggregation?

The winner of the Nobel Prize in Physiology or Medicine 1986, Rita Levi-Montalcini, already commented: "The burden of neurological disorders is reaching a significant proportion in countries with a growing percentage of the population over 65 years". Effectively, aging is considered the main risk factor for these ND and many scientists point out that the probability of suffering any of them doubles past the age of 60 . However, there are other influences, genetic and environmental, whose complex interaction may trigger neurodegeneration at any age.

Within the last years, particular attention has been placed on the functional interaction between the gut microbiota, including its metabolites, and the central nervous system (CNS). On one hand, CNS regulates intestinal function via afferent and efferent autonomic pathways. On the other hand, the sympathetic and parasympathetic nervous system of the gut, together with the vagus nerve, connects the enteric nervous system (ENS) and the hypothalamic-pituitary-adrenal axis (HPA) with the CNS [5-7]. This a priori beneficial bidirectional communication can become harmful due to an imbalance in the microbiota composition, i.e., symbionts/pathobionts ratio, which seems to influence the development and progression of various ND, proteinopathies among them. Under this perspective, this review attempts to provide an updated view of the role that gut microbiota poses in the pathogenesis of the most common neurodegenerative proteinopathies, and of the possibility of translating this knowledge into effective therapeutic treatments. 


\section{The microbiota and microbiota-based therapies}

The human body constitutes a true ecosystem composed of trillions of microorganisms that inhabit on or within us. This microbiota is a long-term evolutionary human partner that has strongly influenced its evolution and adaptation to the environment [8-10]. Undoubtedly, the gut hosts the largest number of microbes of the human body. Despite its complexity, progress in high-throughput sequencing techniques have led to this microbial community being the best characterized so far [10-12]. The gut microbiota harbours a huge variety of microorganisms, like bacteria, fungi, amebae, archaea, protozoa and viruses, that exist in a mutualism symbiosis with the human host [7, 13, 14]. Bacterial species dominate the gastrointestinal tract (GIT), and Bacteroidetes and Firmicutes are the two phylotypes most represented. However, small amounts of Proteobacteria, Actinobacteria, Fusobacteria, Cyanobacteria and Verrucomicrobia phyla can also be found $[10,15,16]$. The role of microbiota in the human health has been widely studied. In fact, energy homeostasis, metabolic processes such as vitamin synthesis or producing short-chain fatty acids (SCFAs), deconjugation of bile acids, or protecting against colonization by pathogens and immunologic reactions are just some of a large number of human activities in which microorganisms are involved [13, 14, 17].

The gut colonisation begins at the moment of birth when the sterile infant GIT is exposed to maternal and environmental microbiota. From that time, and during the first years of life, the gut microbial population undergoes a maturation process until reaching the stable composition and diversity that of the adult. This primocolonisation is influenced by diverse factors such as gestational age, mode of delivery (vaginal birth or C-section), diet (breast or formula milk), antibiotic therapy or surrounding environment, and maternal health conditions. This early life microbiota modifications, that occur in a key window for the host development, can have short and long impacts on the host. Moreover, during the lifespan, physiological conditions differ widely into human gut leading to a different concentration and diversity of microorganisms through the GIT [18]. This fact makes the faecal microbiota of each adult human individual unique, being considered as a personal "fingerprint" $[10,14,16,19]$. Despite these high inter-individual variations, the microbiota is highly stable through time, especially at functional level, and the enteric microbiota role in homeostasis and host health is generally conserved. Advanced experimental efforts have demonstrated a strong association between altered gut microbiota and its metabolites in the pathogenesis and the progression of gastrointestinal, metabolic and various neurodegenerative and neuropsychiatric diseases [12, 14, 20,21]. These efforts include not only new analytical techniques in microbiology and bioinformatics, but also pivotal collaborative projects, including the Human Microbiome Project [22] or the Metagenomics of the Human Intestinal Tract (MetaHIT) project [23]. Besides essential or beneficial microbiota, gut is colonized permanently or occasionally by bacteria that can become opportunistic pathogens if the occasion arise [24]. Therefore, the pathological imbalance of the optimal gut microbiota composition, named dysbiosis, leads to an overgrowth of harmful bacteria and ultimately to a disruption of the host-microorganism homeostasis [25-27].

The concept of microbiota equilibrium has been the basis of new preventive strategies involving dietary interventions that modify altered microbiota to limit potentially dangerous disruptions: microbiota-based therapies. In this case, we can find the use of beneficial microorganisms (probiotics and live biotherapeutics), substances that promote the growth and/or activity of bacteria that contribute to host well-being (prebiotics), and a combination of both (synbiotics) [28]. Furthermore, the use of beneficial bacteria could be independent of microbiota modulation. Indeed, the classical definition of probiotics (live microorganisms that, when administered in adequate amounts, confer a health benefit on the host) refers mostly to the potential direct effect of bacteria on the host without considering the possible modulation of the microbiota.

\section{The microbiota-gut-brain-axis}

Different studies in last decades have evidenced a dynamic cross-talk between gut microbiota and CNS, known as gut-brain axis (GBA), which is critical in brain development, in some processes as neurogenesis and microglial activation, and in modulating host behaviour [21,29] (Figure 1). This bidirectional communication 
is far from simple since different pathways (i.e., immune, neural, endocrine, or metabolic) coexist in an intricate network that links GIT and brain. The most direct way to maintain this communication implies the ENS and the autonomic nervous system (ANS). On one hand, the sympathetic and parasympathetic nervous system links gut with CNS. On the other hand, CNS regulates gut function (immunity, permeability, or mucus secretion) via afferent and efferent autonomic pathways [5, 6]. However, enteric microorganisms can also indirectly influence the brain function by other routes: i) immune system activation mediated by cytokine molecules, ii) hormones and metabolic products of microbial activity such as SCFAs (e.g., propionate, butyrate and acetate) transmitted to distant organs as the brain, and iii) neurotransmitters and other neuroactive molecules of microbial origin (e.g., serotonin, melatonin, histamine or acetylcholine) able to cross the intestine mucosal layer and to orchestrate brain functions $[7,10,15,20]$. Finally, some authors pointed out that the HPA axis seems to influence the GBA via neuroendocrine connections. In fact, the activation of the HPA system in response to environmental (psychological or physical) stressors triggers the secretion of cortisol from adrenal glands which negatively affects brain function, gut microbiota composition and GIT permeability [30-32].

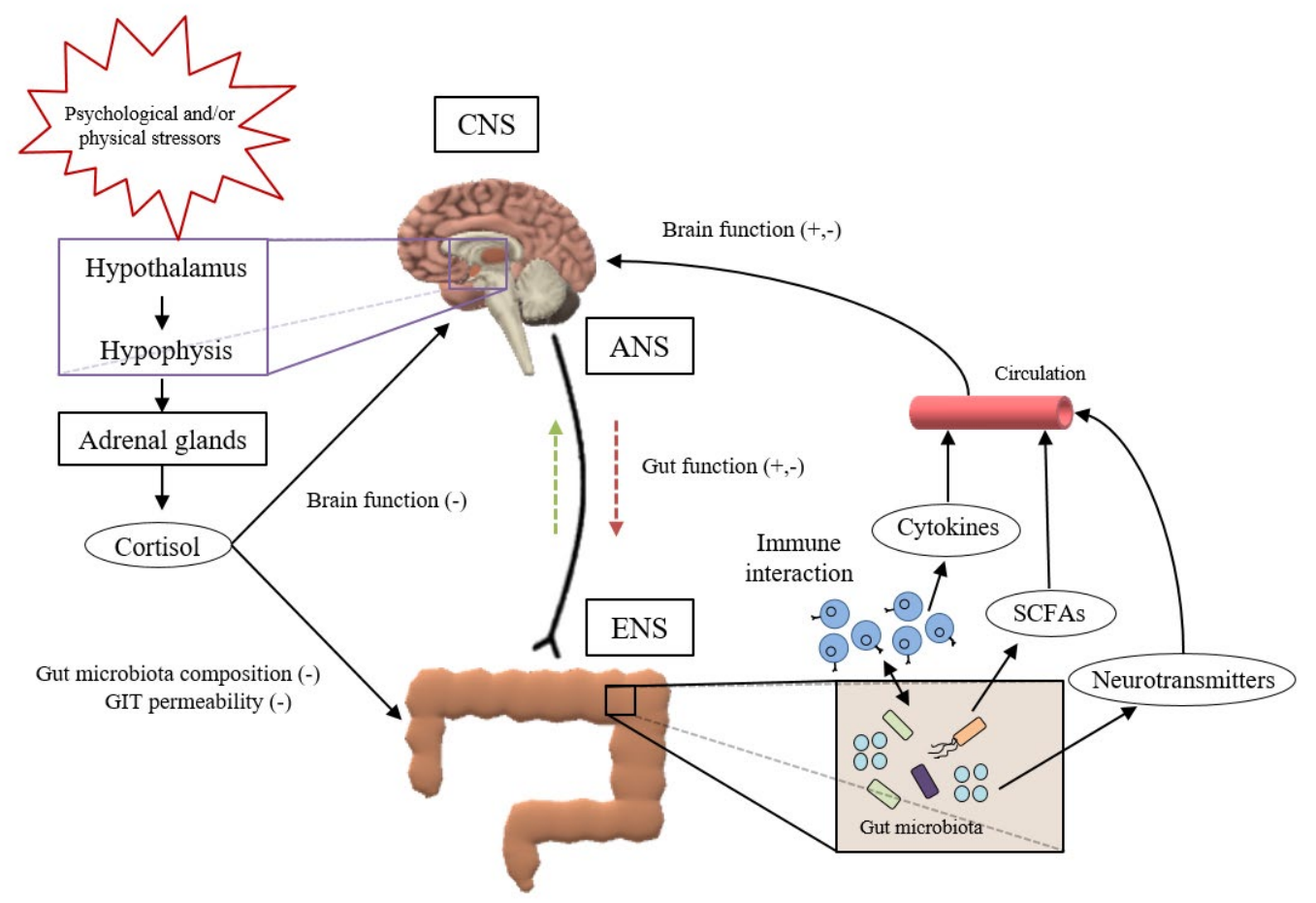

Figure 1. Schematic representation of the intricate network that links GIT and brain, forming the so-called microbiota-gut-brain-axis

\section{Gut microbiota in brain development and function}

The advance in understanding the modulatory effect of microbiota in GBA signalling has required the adoption of new and innovative instruments. Perhaps, the most convincing approach to overcome this issue is the use of germ-free (GF) mice. GF animals display very different morphological, physiological, and immunological characteristics, which underscores the importance of the microbiota in host homeostasis [33]. Focusing in the GBA, GF mice display an impaired HPA activity, an increased stress reactivity and augmented levels of cortisol that contribute to the anxiety-like behaviour that characterizes these animals $[30,34,35]$. Moreover, alterations in the serotoninergic signalling due to changes in tryptophan levels, the precursor of serotonin, would be behind of the memory and cognition dysfunction that GF mice suffer [6, 36-38]. Similarly, variations in synaptic transcriptome have been observed in GF versus control mice. For example, it has been demonstrated increased hippocampal levels of the dopamine receptor subunit Drd1a and reduced amounts of glutamate receptor subunits ( $\mathrm{Nr} 1$ and $\mathrm{Nr} 2$ ) in cortex, hippocampus and amygdala [39]. In addition, augmented expression of myelin related genes and hypermyelination in the prefrontal cortex have been described in GF mice [10]. Nevertheless, mice growing in a "sterile bubble", as it is the case of GF mice in most of the axenic animal facilities, show a myriad of neural disturbances, compared with those conventionally housed, that 
seem to influence some cognitive and brain functions (reviewed in [39-41]). This fact, join to the complexity of managing GF mice, has extended the use of altered microbiota murine models (i.e., animals treated with antibiotics, exposed to specific bacterial species or pathogens, or transplanted with faecal microbiota at some time points across their lifespan) as a good alternative to GF mice to study the impact of the microbiota on the GBA [6, 39]. For instance, it has been found that the partial or total lack of gut microbiota correlates with an increase in adult hippocampal neurogenesis [42], alterations in blood brain barrier (BBB) permeability [43], $\alpha$-syn aggregates and a significant downregulation of microglia gene profile [10, 25, 44, 45].

At this point, some questions arise: (i) are microbial-induced alterations in the GBA reversible? (ii) is it possible to use dietary interventions that modulate the microbiota to prevent GBA microbial-induced alterations? In this sense, Ait-Belgnaoui et al. [46] observed that the increase in BBB permeability was prevented when they pre-treated animals with Probio'Stick ${ }^{\circledR}$, a probiotic mixture of Bifidobacterium longum R0175 and Lactobacillus helveticus R0052. Similar results were obtained after administration of a butyrateproducing bacteria, Clostridium tyrobutyricum, to GF mice [43]. In the rigorous work of Erny et al. [44], the authors concluded that "recolonization with a complex microbiota partially restored microglia features" and that "short-chain fatty acids (SCFA), microbiota-derived bacterial fermentation products regulated microglia homeostasis". Indeed, very recent studies have confirmed that early exposure to probiotics, and other bacterial derivatives that affecting GBA, reduces the exacerbated HPA axis response to stress and prevents changes in hippocampal neurogenesis and synaptic plasticity [24, 27, 47].

\section{Role of gut dysbiosis in proteinopathies: molecular mechanisms and clinical applications}

Converging evidence strongly suggests that accumulation of protein aggregates, neuroinflammation and oxidative stress play a fundamental role in the complex aetiology and pathophysiology of different proteinopathies as AD, PD and HD. Nowadays, it is quite straightforward to establish a direct link between neurodegeneration and aging, and how the broad spectrum of age-related changes, in terms of lifestyle habits (e.g., diet, stress, environmental factors, etc.), influences the risk of developing ND. The current lack of effective treatments has to do with the fact that exact mechanisms underlying their pathogenesis are still unclear. In this sense, finding new and effective therapeutic tools constitutes a major challenge to neuroscientists.

The involvement of gut dysbiosis in the onset and development of neurodegenerative proteinopathies has drawn a lot of attention in last decades. It is well-known that intestinal microbiota experiences a reduction in diversity composition during aging and in aged-related ND. Although with high interindividual variability, the relative proportions of pathogenic and beneficial bacteria change, i.e., Firmicutes and Bifidobacteria numbers decrease, and Enterobacteriaceae and Bacteroidetes increase [20,48]. But these fluctuations are not only related to aging but also to decline in health status, malnutrition, and high rate of medication in the elderly. Regardless of the cause, alterations in the optimal microbial composition of aging patients suffering from ND result in a compromised microglial reaction, the weakening of the GIT barrier function and the disruption of the BBB integrity which leads to a serious recrudescence of inflammatory processes in the brain $[21,43,49]$ (Figure 2). The new understanding of the involvement of gut dysbiosis in the pathogenesis of some proteinopathies and possible microbiota-based intervention strategies with therapeutic potential will be treated in the following sections.

\section{PD}

PD is the second most common ND, which affects 1-2\% of people over 65 years of age. This multifactorial neurodegenerative disorder, first described by James Parkinson in 1817, is characterized by a progressive death of dopamine-producing neurons in the SN pars compacta [50]. Like other well-defined proteinopathies, the affected brains exhibit typical aggregations of $\alpha$-syn, known as Lewy bodies, that trigger neuronal death and compromise dopamine secretion in motor control areas [51,52]. Motor characteristic PD symptoms as bradykinesia, tremor or postural instability are basically related with this dopamine loss. Besides cognitive alterations, constipation stands as a prevalent and early non-motor manifestation of PD (> 80\%) 
that appears even before motor disturbances [53]. Regardless of the type of PD, i.e., familial early-onset PD caused by inheritable genetic factors or the most frequent idiopathic cases [54-57], effective anti-PD therapies exist for symptom relieving and include both pharmacological and surgical interventions [58-60]. Although levodopa ( $L$-DOPA) remains the treatment of choice for PD, disabling motor complications (i.e., on-off phenomena, dyskinesia or dystonia) emerge after some years of chronic administration. Alternative treatments as dopaminergic agonists (amantadine, apomorphine, bromocriptine, cabergoline, lisuride, pergolide, pramipexole, ropinirole, rotigotine), monoamine oxidase B (MAO-B) inhibitors (selegiline and rasagiline) or catechol- $O$-methyltransferase (COMT) inhibitors (entacapone, tolcapone), are generally less effective than $L$-DOPA but show fewer motor adverse effects $[61,62]$. Deep brain stimulation or magnetic resonance imaging (MRI)-guided focused ultrasound are among neurosurgical procedures provide the greatest benefits for patients $[62,63]$. Unfortunately, no disease-modifying treatments are available so new therapies are essential to improve life quality of those suffering from PD.

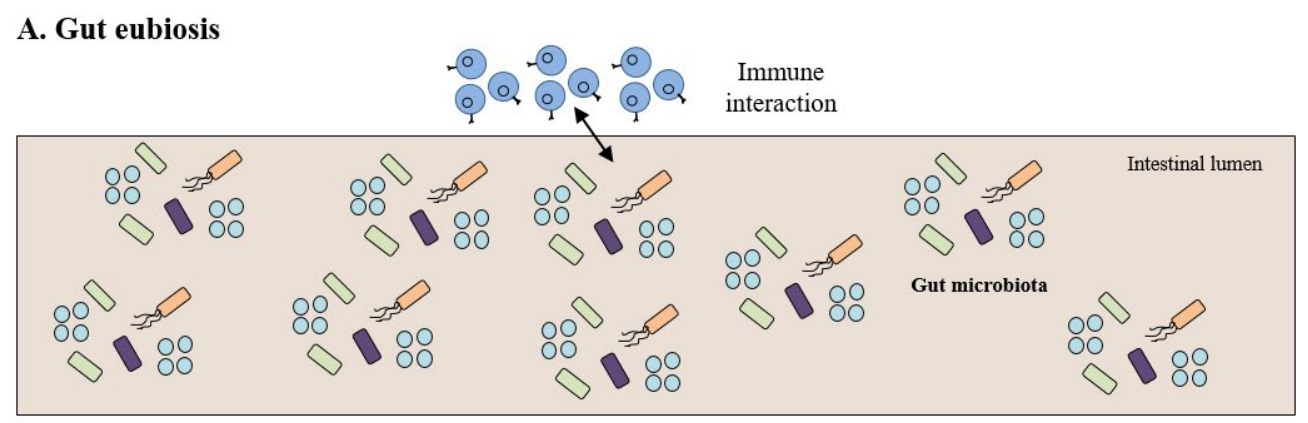

\section{B. Gut dysbiosis}

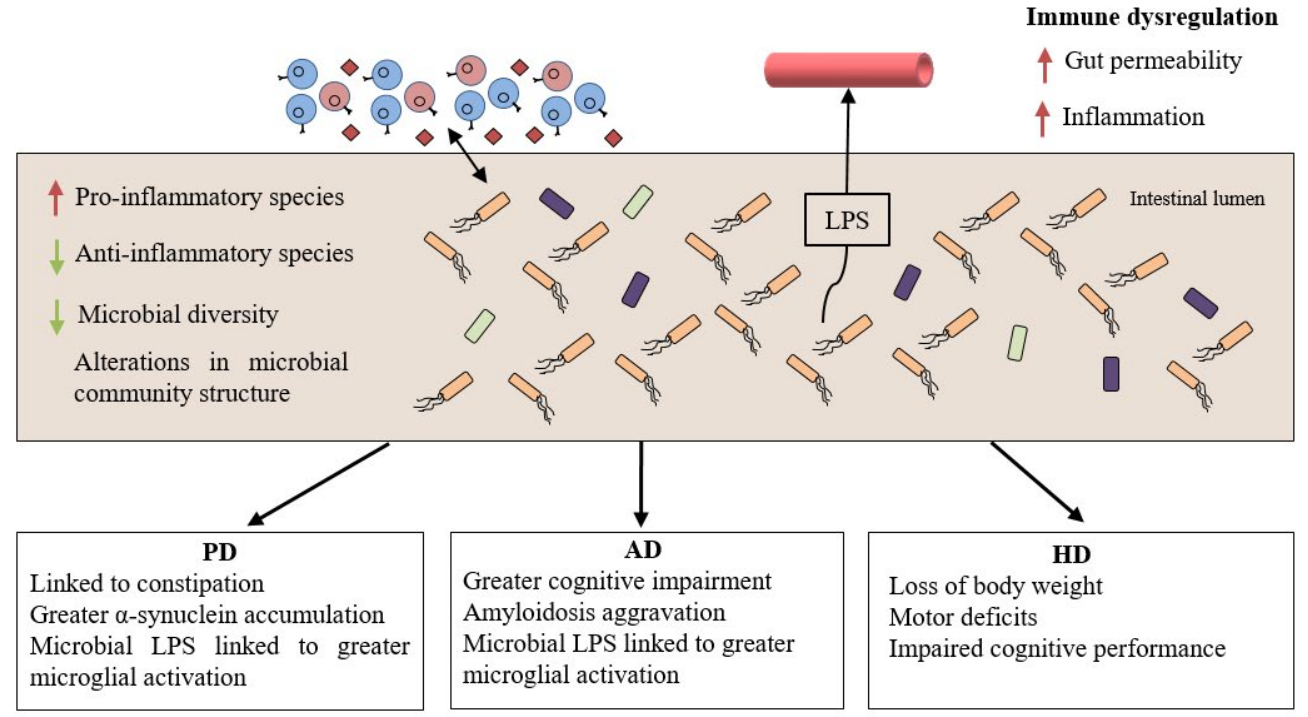

Figure 2. Gut dysbiosis linking to the pathogenesis of neurodegenerative proteinopathies. A) Normal cross-talk between intestinal immune system and gut microbiota under non-pathological conditions; B) gut microbiota unbalance leading to immune dysregulation under pathological conditions which ultimately influences the clinical manifestations of the proteinopathies. LPS: lipopolysaccharides

Pioneering studies in last decades suggest that the initial step in PD pathogenesis might occur in the GIT since alterations in the gut function as constipation, dysphagia, nausea, or gastroparesis have been observed in patients long before the typical motor symptoms [64]. In this way, it has been postulated that gut dysbiosis and the consequent interruption in the beneficial relationship between the microbes of the intestine and CNS may be linked to the onset and progression of the disease [53, 65-67]. Certain separate lines of evidence converged to establish this. First, epidemiological studies of vagotomised patients showed a significant decrease in the risk of developing PD when compared with general population $[39,68]$. Second, analyses in PD patients described alterations in microbiota composition compared to age-matched healthy 
controls. For instance, some authors found reduced levels of anti-inflammatory bacteria Prevotellaceae, Blautia, Coprococcus, and Roseburia and a greater abundance of pro-inflammatory Enterobacteriaceae. In fact, a decrease in Prevotellaceae family members, who are well-known to be mucin and neuroactive SCFAsproducers, leads to alterations in gut permeability and susceptibility to bacterial endotoxins. In contrast, the higher levels of Enterobacteriaceae species seem to be related with inflammation and the severity of motor dysfunction in PD $[13,53,66,69,70]$. Third, in addition to microorganisms themselves, some gut-derived pro-inflammatory bacterial products as LPS can also be involved in the progression of the proteinopathy. Among others, Guo and co-workers [71] demonstrated by in vitro and in vivo models of PD that LPS penetrates into the blood through a compromised epithelial barrier and induces the microglial expression of inflammatory cytokines, such as tumour necrosis factor (TNF- $\alpha$ ) or interleukin (IL)-1b and IL-6, which alter the BBB and promote $\alpha$-syn neurodegenerative accumulation in the SN pars compacta. More recently, Song and colleagues [72] have postulated that interaction between $\alpha$-syn and some bacterial toxicants is central in the exacerbated gut microbiota disruption and dopaminergic neuron loss showed by transgenic mice overexpressing human $\alpha$-syn. Importantly, high levels of LPS in brain and serum of PD patients have been frequently described in clinical trials [73-76]. Fourth, according to the hypothesis of Braak et al. [67], the pathological accumulation of $\alpha$-syn could start in the ENS spreading to the brain through the vagus nerve $[67,77]$. In this sense, gut-derived pro-inflammatory factors could induce the expression and misfolding of $\alpha$-syn. It has been observed histologically identical inclusions to Lewy bodies in enteric neurons of both submucosal (Meissner) and myenteric (Auerbach) plexuses following a hypothetical rostral-caudal gradient $[78,79]$. Indeed, inoculation of $\alpha$-syn isolated from brains of PD patients or $\alpha$-syn preformed fibrils into the gastric wall of healthy rodents resulted in Lewy body-like brain aggregates and in motor deficits [80, 81]. Intriguingly, Sampson et al. [82] confirmed that faecal microbiota transplantation (FMT) from PD patients reproduced motor symptoms in GF mice. Finally, there is evidence that small intestinal bacterial overgrowth (SIBO) and Helicobacter pylori infection are triggering factors in PD [66, 83-86]. Satisfactory treatment of SIBO and eradication of Helicobacter pylori would be related to the long-lasting improvement in motor and intestinal indicators of patients, probably due to greater efficiency in $L$-DOPA absorption $[79,87,88]$.

Bearing in mind all the data, it is not surprisingly that by normalizing and maintaining a balanced gut microbiota composition, PD pathological processes could be reduced and even act as a preventive factor. In fact, by taking advantage of microorganisms that inhabit the GIT as a target to mediate beneficial brain effects, different microbial-based treatments have displayed efficacy in the reduction of symptoms in PD patients. These live biotherapeutics include probiotics, prebiotics, synbiotics, and postbiotics, and can be administrated through diet by supplements or functional foods (a precise definition of those terms can be found in [24, 89]). Although preclinical and clinical studies are limited, it is shown that probiotics containing Lactobacillus casei Shirota and different Bifidobacterium strains significantly improve GIT symptoms in PD patients [79, 89-91]. Recent randomized, double blind, placebo-controlled clinical studies go in the same direction and evidence that some probiotic formulations (tablet, capsule, or drinkable formats) have success in ameliorating motor clinical symptoms and biochemical profiles in PD [92] (https://parkinsons-london. co.uk/academic-observational-studies/). Interestingly, and according with recent studies in MPTP- and rotenone-induced models of PD, the rescuing effects of a probiotic mixture (Lactobacillus and Bifidobacterium species) in the prevention of dopaminergic neuronal degeneration may be partially due to both, increased levels of neurotrophic factors [e.g., brain-derived neurotrophic factor (BDNF) and glial cell line-derived neurotrophic factor (GDNF)] and to bacteria-derived butyrate in the brain [93]. Moreover, the regular intake of Bacillus spp., among other bacterial treatments, may increase dopamine levels since this probiotic group can convert $L$-tyrosine into $L$-DOPA in a reaction mediated by tyrosine decarboxylase $[66,94,95]$. Finally, in a placebo-controlled clinical trial in 120 patients with $\mathrm{PD}$, the authors found a significant improvement in constipation and other GIT-related symptoms after regular consumption of a synbiotic, containing different probiotic strains and prebiotic fibers, compared with those patients given placebo [96].

Not only probiotics or synbiotics contribute to a healthy gut microbiota composition but dietary interventions [12, 97, 98] or traditional medicines are also noteworthy. For example, mercury sulfide- 
containing Hua-Feng-Dan and 70W Zhen-Zhu Wan (70W, Rannasangpei) have been included among the Ayurveda, Tibetan and Chinese medicines used for the treatment of neurological disorders for more than 300 years. Now, it has been proven that these medicinal recipes exert their neuroprotective effects by reducing gut microbiota disturbances in mouse and rat models of PD [99, 100].

Finally, a recent innovative and effective way to restore gut microbiota ecosystem in PD patients is the FMT; stool samples from healthy donors are transferred to the GIT of individuals suffering from PD. Studies on the benefits of FMT to mitigate constipation and also non-GIT symptoms of PD with seemingly fewer side effects are increasingly available [101, 102]. However, the US Food and Drug Administration (FDA) has recently issued an alert concerning the risk of transmission of pathogenic bacteria and serious life-threatening infections with the use of FMT $[103,104]$ (https://www.fda.gov). Further studies are needed to probe its real benefit as a therapy to combat/prevent PD.

\section{$\mathrm{AD}$}

$\mathrm{AD}$ is the most devastating and common form of dementia that may contribute, according to recent estimates, to $60-70 \%$ of cases; its prevalence stands at around $5-8 \%$ in people over 65 years of age which rises to $25-50 \%$ above 75 years [105]. This chronic neurodegenerative disorder is characterized by a progressive loss of memory, language and learning capabilities leading to severe disability in daily activities, a myriad of symptoms already documented in detail by Alois Alzheimer between 1906 and 1911 in patients who had died of an unusual mental illness [106]. Cognitive deficits are a reflection of inflammatory processes, loss of neurons and progressive impairments in synaptic function in some brain areas, mainly in frontal cortex and hippocampus $[107,108]$. Notably, two types of protein aggregations namely amyloid plaques and neurofibrillary tangles are responsible for this mixed proteinopathy, being also considered as the pathological hallmarks of the disease. Senile plaques result from abnormal processing of the amyloid precursor protein (APP) leading to extracellular accumulation of misfolded A $\beta$, whereas neurofibrillary tangles consist of intracellular accumulations of hyperphosphorylated tau protein; both contribute significantly to loss of cholinergic neurons, axonal degeneration and synaptic failure associated with the pathology [109-111]. Interestingly, many lines of evidence have demonstrated that cerebrovascular dysfunction also contributes in a direct way to AD pathogenesis. In fact, some theories point out that damage of cerebral blood vessels, BBB breakdown, changes in permeability and diminished brain perfusion would be key in the $A \beta$ accumulation and neuronal degeneration in AD brains (reviewed in $[112,113]$ ).

AD appears predominantly in a sporadic fashion, but a small number of patients suffers from the familial variety of the disease with inheriting mutations that lead to early-onset cases [55, 109, 114, 115]. Despite recent advances in research, there is still no precise comprehension of the dementia disease burden and current therapies only provide modest symptom relief. The few anti-AD drugs approved are intended to increase acetylcholine levels (e.g., cholinesterase inhibitors as donepezil, galantamine or rivastgmine) or decrease the overall $N$-methyl- $D$-aspartate (NMDA) glutamate receptors activity (e.g., NMDA receptor antagonist as memantine) in CNS, which seems to temporarily improve cognitive performance and/or slow down the disease progression in some people $[116,117]$. Moreover, treatments aiming at decrease the $A \beta$ or tau burden by using antibodies for plaque clearance or tau aggregation inhibitors (TAIs) have not been proven effective in patients due to different reasons $[118,119]$. Since the global number of people living with $\mathrm{AD}$ is increasing with devastating consequences for families, communities, and health-care systems around the world, intensive research has been focused on searching for new therapeutic targets that could prevent neurodegeneration and/or improve cognition in $\mathrm{AD}$.

In vitro and in vivo assays have demonstrated the impact of microbiota dysbiosis in the development of AD. Part of the current knowledge about the potential link between gut microbiota and this proteinopathy comes from the study of Bruce-Keller and collaborators [120], who found an impairment in the cognitive behavioural capacity of mice undergoing an antibiotic therapy and injected with gut microorganisms from mice fed with a high-fat diet. Similarly, an age-related abnormal gut microbiota composition seems to be associated with the compromised cognitive function in senescence-accelerated mouse prone 8 (SAMP8) mice $[121,122]$. Although limited, the studies made so far have been enough to prove important alterations 
in the intestinal microbial profile in AD patients compared to control age- and sex-matched individuals. On one hand, it has been described a reduction in diversity of gut microbiota, i.e., low levels of Firmicutes and Bifidobacterium and higher amount of Bacteroidetes [123], and differences in Firmicutes:Bacteroidetes ratio [124]. On the other hand, Helicobacter pylori infection has been associated with a greater cognitive decline in $\mathrm{AD}$ patients and its eradication with a decreased risk of $\mathrm{AD}[125,126]$. A detailed analysis of faecal microorganisms of subjects suffering from cognitive impairment and brain amyloidosis also demonstrated a larger proportion of pro-inflammatory Escherichia/shigella spp. taxa and a lower proportion of antiinflammatory Eubacterium rectale spp. taxa compared to healthy controls [127]. This altered gut microbiota composition has a profound effect on the brain function modulating microglial activation and contributing to $A \beta$ pathology [128]. Something that is not generally considered is that a significant percentage of total $A \beta$ content of the brain is generated peripherally by many of the microorganisms that colonize our intestine [129]. This peptide, as well as other molecules of bacterial origin like lipoproteins or LPS, are able to cause a chronic inflammation, by the release of various microglial pro-inflammatory mediators (iNOS, ROS, COX-2, and NF- $\mathrm{KB}$ ), that impact the permeability of GIT and compromises BBB integrity $[128,130]$. Consequently, increased levels of peripheral $A \beta$ together with a decreased capacity of protein clearance seem to potentiate fibrillogenesis and $A \beta$ aggregation in the brain $[124,129,131,132]$. A positive correlation between serum levels of LPS and cognitive impairment in AD patients has been also demonstrated [15].

Simultaneously, the pioneering studies of Harach and colleagues [133], in a GF mouse model of AD (GFAPP/PS1), were instrumental for analysing potential microbiota-based AD therapies. In fact, they observed that transgenic mice raised under GF conditions exhibit a diminished $A \beta$ pathology and low levels of inflammation in the CNS when compared to conventionally housed AD animals. Interestingly, the transference of stool samples from conventionally-raised APP/PS1 mice to GF-APP/PS1 ones resulted in a markedly accumulation of cerebral senile plaques [133]. Further, changes in gut microbial composition by prolonged antibiotic therapies significantly reduced $A \beta$-induced neurodegeneration and neuroinflammation [134]. Preventive effects on $A \beta$-induced cognitive deficits were also observed in mice orally administered with Bifidobacterium breve A1 strain prior to the intracerebroventricular injection of $A \beta_{25-35}$ [135]. Likewise, other probiotics (e.g., SLAB51, VSL\#3, ProBiotic-4), prebiotics (e.g., fructooligosaccharide, xylooligosaccharides, ferulic acid), synbiotics (e.g., a mixture of xylooligosaccharides and Lactobacillus paracasei HII01) and, even dietary and traditional medicine interventions (e.g., oligosaccharide fractions derived from Liuwei Dihuang decoction) are potentially neuroprotective in different models of aging as SAMP8 mice [136-138] and other murine age-linked models of the AD etiopathogenesis [139-146], alleviating the main age-related symptoms of the disease and delaying its progression. This fact seems to reflect deeper changes at biochemical level, i.e., a decreased microglial activation, inflammation, oxidative stress and $A \beta$ accumulation, increased levels of hippocampal BDNF and of genes involved in synapse processes [40, 145, 146].

Probiotics have also proven to have some success in ameliorating AD-related symptoms in some human studies (see the exhaustive reviews of $[40,47])$. A specific multibiotic of four strains $(L$. acidophilus, L. casei, B. bifidum, and L. fermentum) given over a course of 12 weeks to an AD cohort in a double-blind randomized controlled trial led to improvements in cognition according to Mini-Mental State Examination Score (MMSE) [147]. However, a similar intervention using other Lactobacilli and Bifidobacterium combinations (e.g., L. fermentum, L. plantarum, B. lactis, or L. acidophilus, B. bifidum, B. longum) demonstrated the insensitivity of severe cases of AD to this treatment [148]. In a recent study of Tamtaji and co-workers [149], an AD cohort was randomly supplemented with either a probiotic mixture (L. acidophilus, B. bifidum, and B. longum) combined with selenium as prebiotic, selenium alone or placebo. Their findings showed enhancements in the MMSE and a significant reduction in metabolic markers of inflammation, oxidative stress, insulin metabolism and dyslipidemia, following synbiotic administration compared with prebiotic alone or placebo [149]. In addition, the daily consumption for 90 days of probiotic-fermented kefir was effective in the improvement of anti-/pro-inflammatory cytokine and anti-/pro-oxidant ratios in $\mathrm{AD}$ patients which seems to be behind the higher scores on all cognitive tests [150]. Finally, the efficacy of FMT was evaluated in both mouse models of AD and clinical trials. It has been shown that infusion of faecal material from wild-type mice in the gut of APPswe/PSEN1dE9 or 5XFAD 
transgenic mice positively modifies some typical biomarkers of the disease. In this sense, FMT reduced phosphorylation of tau protein and the brain levels of $A \beta$, increased synaptic plasticity and decreased COX2 and other pro-inflammatory molecules, resulting in a remarkable cognitive improvement [151-153]. To our knowledge, only a case report has been published until now. This is just a proof of concept for one patient of 82-year-old who experienced a rapid and surprising improvement in AD symptoms after undergoing an FMT from a healthy donor to treat a recurrent Clostridioides difficile infection [154]. Nevertheless, at least two randomized placebo-controlled trials with FMT in AD patients are ongoing and registered on ClinicalTrials. gov at the time of writing this review.

Despite the promising results that different gut microbiota-targeted interventions have demonstrated in some researches, further humanized studies are required to establish unequivocally their safety and therapeutic potential in AD.

\section{HD}

HD is an autosomal-dominant rare neurodegenerative genetic disorder that appears in mid-life with fatal consequences. Given its heritability, HD affects $50 \%$ of the patients' progeny with a variable age of onset (30-50 years) and a maximal life expectancy of 15-25 years after diagnosis [155]. The pathology is caused by a trinucleotide repeat of cytosine-adenine-guanine (CAG) in the HTT gene which encodes for the HTT protein; whereas the length of CAG is 16-20 repeats in normal conditions, in the case of the mutant protein [mutant HTT (mHTT)] it reaches more than 36 repeats [156]. Although the exact physiological role of the HTT is unknown, its mutations result in a polyglutamine (polyQ) expansion in the N-terminus that leads to impaired protein folding and consequently to its self-aggregation into cytotoxic cytoplasmic and nuclear inclusions [157-160]. The acquisition of new pathogenic properties by the mutant protein and the loss of function of the wild-type HTT protein have been associated with degeneration of inhibitory neurons in some structures of basal ganglia, as striatum, which is accompanied by a secondary neuronal death in SN, cerebral cortex, hippocampus or cerebellum $[161,162]$. Overall, these brain changes are behind the clinical manifestations of HD including psychiatric (depression), cognitive (dementia), and characteristic motor alterations (chorea) with hyper- and hypokinetic phases [163]. The mechanism of disease progression is not clear and, unfortunately, there is no curative treatment for HD. The main goal of currently therapeutic approaches, some of them still under study, is to reduce symptoms and maintain the quality of life of patients as much as possible $[162,164]$. Notable, among them, are the use of dopamine inhibitors, anti-excitotoxic compounds and antipsychotics drugs, and also those actions designed for achieving the enhancement of BDNF expression or the reduction of mHTT burden [164-166].

In addition to motor and cognitive dysfunction, a high percentage of HD patients co-presents a wide range of GIT clinical symptoms including diarrhea, nutrient deficiencies or gastritis, that have been ignored for a long time $[163,167,168]$. Thus, despite the extensive evidence of gut dysbiosis in other proteinopathies as $\mathrm{AD}$ and mainly PD, few studies have raised this issue in the case of HD. In the last years, some preclinical work has reported altered gut microbiota profiles in some animal models of HD [169]. However, it was not until the year 2018 when Kong and co-workers [170] demonstrated it for the first time. In fact, they found changes in gut microbiota composition and microenvironment in R6/1 transgenic mice showing an increased level of Bacteroidetes and a decreased amount of Firmicutes. Moreover, this gut dysbiosis seemed to be related with loss in body weight and motor deficits in HD mice at 12 weeks of age. These results, alongside to an impaired intestinal permeability, were subsequently confirmed in transgenic R6/2 HD mice in early and early/mid stages of disease [171]. Furthermore, the BACHD mouse model of HD placed in a GF conditions exhibited defects in myelin plasticity [172]. Finally, the pioneering study of Wasser et al. [173] has become the first direct evidence of gut dysbiosis in people with HD; the authors highlighting the existence of important alterations in the gut microbial community structure, i.e., differences in richness and diversity, associated with cognitive performance and motor signs in HD patients compared with age- and gender-matched healthy controls. In summary, with regard to HD, there is an urgent need for further research to uncover the exact relationship between gut dysbiosis and the disease that could lead to new microbiota-targeted therapies, as in the case of other proteinopathies. 


\section{Perspectives and conclusions}

Nowadays, the existence of a link between the gut microbiota and the brain function of the host is beyond doubt. This review compiles a significant number of verified evidences that are instrumental in highlighting the key role of microbiota colonization in the neurodevelopment, and how disturbances in microbiota dynamics are able to impact brain function in an age-dependent way. Thus, changes in microbiota composition during infancy and childhood are related with the risk of developing neuropsychiatric disorders later in life (a complete survey of this topic is beyond the scope of this paper and the reader is referred to $[21,174,175]$ for further details), and ageing can influence the onset of some ND.

Perhaps the greatest exponent of healthy aging is constituted by those people who reach 100 or more years of age with a lower number of comorbidities and a better health condition, either physical and/or mental status, the so-called "centenarians". Interestingly, some authors using next-generation sequencing approaches demonstrated that gut microbiota of centenarians markedly differs from elderly population in composition, i.e., they showed decreases in Faecalibacterium, Roseburia, Coprococcus, Blautia. Furthermore, increases in Enterobacteriaceae, Christensenellaceae, Akkermansia and Bifidobacterium, and in functionality with a propensity for proteolytic rather than carbohydrate metabolism were observed [176-178]. This may suggest that rearrangements in gut microbiota in the final stage of life could promote healthy aging and longevity, pointing out some bacterial groups, such as Christensenellaceae and Akkermansia, as bacterial signatures of a healthy eldering. In a totally opposite situation are people who suffer from some type of agerelated ND, proteinopathies among them. In fact, pathological alterations in the gut microbiota composition have been demonstrated in these patients compared with healthy controls. In this sense, gut dysbiosis and the consequent disruption of beneficial relationship between microorganisms that inhabit the GIT and CNS may contribute to the onset and progression of some proteinopathies (Figure 2). More importantly, most studies in this field suggest that influence GBA by bacteria and bacterial derivatives impacts several symptoms and hallmarks of PD, AD and HD, so it could be a promising new therapeutic option in their clinical management $[12,13,15,21,179]$. These potential microbiota-based therapies would include the intake of adequate amounts of different bacterial strains or substances inducing the growth/activity of microbiota (probiotics, prebiotics or synbiotics), or to replacing the entire gut microbial population with a new intact one by FMT $[40,47]$ (Table 1). However, there are still uncertainties associated with the use of these therapies; for example, the very limited number of human studies, the high variety in the cohorts employed, or the lack of formulation and dose standardization have disabled their recommendation as biotherapeutics in current medical practice $[103,104,180]$. Indeed, mainly in the case of FMT, safety issues have been revealed by the scientific community for these particularly vulnerable groups that still make difficult to endorse this strategy. Therefore, further research is needed to design safe, effective, and targeted microbiota-based therapies for patients with hard-to-treat proteinopathies.

Table 1. Summarizing documented clinical manifestations, gut microbial profiles, and conventional and new microbial-related therapies in proteinopathies

\begin{tabular}{|c|c|c|c|c|c|}
\hline ND & Hallmarks & $\begin{array}{l}\text { Clinical } \\
\text { manifestations }\end{array}$ & $\begin{array}{l}\text { Conventional } \\
\text { therapies }\end{array}$ & Gut microbial profile & $\begin{array}{l}\text { New microbial-related } \\
\text { therapies }\end{array}$ \\
\hline \multirow[t]{5}{*}{ PD } & \multirow[t]{5}{*}{ Lewy bodies } & \multirow[t]{5}{*}{$\begin{array}{l}\text { Bradykinesia, } \\
\text { tremor or postural } \\
\text { instability } \\
\text { Constipation }\end{array}$} & \multirow{5}{*}{$\begin{array}{l}\text { L-DOPA, } \\
\text { dopaminergic } \\
\text { agonists, MAO-B } \\
\text { inhibitors and } \\
\text { COMT inhibitors }\end{array}$} & \multirow{2}{*}{$\begin{array}{l}\text { Reduction of anti-inflammatory } \\
\text { species and greater } \\
\text { abundance of pro-inflammatory } \\
\text { Enterobacteriaceae }[13,53,66 \text {, } \\
69,70]\end{array}$} & $\begin{array}{l}\text { Probiotic containing } \\
\text { Lactobacillus casei Shirota } \\
\text { and Bifidobacerium strains } \\
{[79,89-91]}\end{array}$ \\
\hline & & & & & \multirow{2}{*}{$\begin{array}{l}\text { Regular intake of Bacillus spp. } \\
{[66,94,95]}\end{array}$} \\
\hline & & & & \multirow{3}{*}{$\begin{array}{l}\text { SIBO and Helicobacter pylori } \\
\text { infection }[79,87,88]\end{array}$} & \\
\hline & & & & & $\begin{array}{l}\text { Regular consumption of } \\
\text { synbiotics [96] }\end{array}$ \\
\hline & & & & & FMT $[101,102]$ \\
\hline
\end{tabular}


Table 1. Summarizing documented clinical manifestations, gut microbial profiles, and conventional and new microbial-related therapies in proteinopathies (continued)

\begin{tabular}{|c|c|c|c|c|c|}
\hline ND & Hallmarks & $\begin{array}{l}\text { Clinical } \\
\text { manifestations }\end{array}$ & $\begin{array}{l}\text { Conventional } \\
\text { therapies }\end{array}$ & Gut microbial profile & $\begin{array}{l}\text { New microbial-related } \\
\text { therapies }\end{array}$ \\
\hline \multirow[t]{8}{*}{$A D$} & \multirow{8}{*}{$\begin{array}{l}\text { Senile } \\
\text { plaques, } \\
\text { neurofibrillary } \\
\text { tangles }\end{array}$} & \multirow{8}{*}{$\begin{array}{l}\text { Progressive } \\
\text { loss of memory, } \\
\text { language } \\
\text { and learning } \\
\text { capabilities }\end{array}$} & \multirow{3}{*}{$\begin{array}{l}\text { To increase } \\
\text { acetylcholine } \\
\text { levels }\end{array}$} & \multirow{2}{*}{$\begin{array}{l}\text { Reduction in gut microbiota } \\
\text { diversity [123] }\end{array}$} & Multibiotics [147] \\
\hline & & & & & \multirow{3}{*}{$\begin{array}{l}\text { Lactobacilli and } \\
\text { Bifibodbacterium } \\
\text { combinations [148] }\end{array}$} \\
\hline & & & & \multirow{3}{*}{$\begin{array}{l}\text { Differences in } \\
\text { Firmicutes:Bacteroidetes ratio } \\
\text { [124] }\end{array}$} & \\
\hline & & & \multirow{5}{*}{$\begin{array}{l}\text { To decrease } \\
\text { NMDA glutamate } \\
\text { receptors activity }\end{array}$} & & \\
\hline & & & & & \multirow{2}{*}{$\begin{array}{l}\text { Probiotic mixture combined } \\
\text { with selenium as prebiotic } \\
{[149]}\end{array}$} \\
\hline & & & & $\begin{array}{l}\text { Helicobacter pylori infection } \\
{[125,126]}\end{array}$ & \\
\hline & & & & \multirow{2}{*}{$\begin{array}{l}\text { Larger proportion of pro- } \\
\text { inflammatory Escherichia/ } \\
\text { Shigella spp. taxa and lower } \\
\text { proportion of anti-inflammatory } \\
\text { Eubacterium rectale spp. taxa } \\
\text { [127] }\end{array}$} & $\begin{array}{l}\text { Daily consumption of } \\
\text { probiotic-fermented kefir [150] }\end{array}$ \\
\hline & & & & & FMT [154] \\
\hline HD & $\begin{array}{l}\text { mHTT } \\
\text { aggregations }\end{array}$ & $\begin{array}{l}\text { Depression, } \\
\text { dementia, motor } \\
\text { alterations and } \\
\text { GIT dysfunction }\end{array}$ & $\begin{array}{l}\text { Dopamine } \\
\text { inhibitors, } \\
\text { anti-excitotoxic } \\
\text { compounds and } \\
\text { antipsychotic } \\
\text { drugs }\end{array}$ & $\begin{array}{l}\text { Differences in richness and } \\
\text { diversity [173] }\end{array}$ & Currently under investigation \\
\hline
\end{tabular}

\section{Abbreviations}

AD: Alzheimer's disease

APP: amyloid precursor protein

$A \beta$ : $\beta$-amyloid peptide

BBB: blood brain barrier

BDNF: brain-derived neurotrophic factor

CNS: central nervous system

ENS: enteric nervous system

FDA: US Food and Drug Administration

FMT: faecal microbiota transplantation

GBA: gut-brain axis

GF: germ-free

GIT: gastrointestinal tract

HD: Huntington's disease

HPA: hypothalamic-pituitary-adrenal axis

HTT: huntingtin protein

\section{L-DOPA: levodopa}

LPS: lipopolysaccharides

mHTT: mutant huntingtin protein

MMSE: Mini-Mental State Examination Score

ND: neurodegenerative diseases

NMDA: $N$-methyl- $D$-aspartate

PD: Parkinson's disease

SCFAs: short-chain fatty acids

SIBO: small intestinal bacterial overgrowth 
SN: substantia nigra

$\alpha$-syn: $\alpha$-synuclein

\section{Declarations}

Author contributions

Conceptualization was agreed by EMP and RM who scanned the literature, retrieved and extracted information from articles referenced in the review. PAG analyzed the literature and also extracted information from articles. EMP and PAG compiled all the information and wrote the first version of the manuscript. RM critically read the manuscript and prepared a second version of the article. All authors edited the manuscript and revised the final submitted version.

\section{Conflicts of interest}

The authors declare that they have no conflicts of interest.

\section{Ethical approval}

Not applicable.

\section{Consent to participate}

Not applicable.

\section{Consent to publication}

Not applicable.

Availability of data and materials

Not applicable.

Funding

Not applicable.

\section{Copyright}

(C) The Author(s) 2021.

\section{References}

1. Bourdenx M, Koulakiotis NS, Sanoudou D, Bezard E, Dehay B, Tsarbopoulos A. Protein aggregation and neurodegeneration in prototypical neurodegenerative diseases: examples of amyloidopathies, tauopathies and synucleinopathies. Prog Neurobiol. 2017;155:171-93.

2. Gandhi J, Antonelli AC, Afridi A, Vatsia S, Joshi G, Romanov V, Murray IVJ, Khan SA. Protein misfolding and aggregation in neurodegenerative diseases: a review of pathogeneses, novel detection strategies, and potential therapeutics. Rev Neurosci. 2019;30:339-58.

3. Marsh AP. Molecular mechanisms of proteinopathies across neurodegenerative disease: a review. Neurol Res Pract. 2019;1:35

4. Bayer TA. Proteinopathies, a core concept for understanding and ultimately treating degenerative disorders? Eur Neuropsychopharmacol. 2015;25:713-24.

5. Collins SM, Bercik P. The relationship between intestinal microbiota and the central nervous system in normal gastrointestinal function and disease. Gastroenterology. 2009;136:2003-14.

6. Carabotti M, Scirocco A, Maselli MA, Severi C. The gut-brain axis: interactions between enteric microbiota, central and enteric nervous systems. Ann Gastroenterol. 2015;28:203-9. 
7. Westfall S, Lomis N, Kahouli I, Dia SY, Singh SP, Prakash S. Microbiome, probiotics and neurodegenerative diseases: deciphering the gut brain axis. Cell Mol Life Sci. 2017;74:3769-87.

8. Huitzil S, Sandoval-Motta S, Frank A, Aldana M. Modeling the role of the microbiome in evolution. Front Physiol. 2018;9:1836.

9. Moeller AH, Li Y, Mpoudi Ngole E, Ahuka-Mundeke S, Lonsdorf EV, Pusey AE, et al. Rapid changes in the gut microbiome during human evolution. Proc Natl Acad Sci U S A. 2014;111:16431-5.

10. Dinan TG, Cryan JF. Gut instincts: microbiota as a key regulator of brain development, ageing and neurodegeneration. J Physiol. 2017;595:489-503.

11. Wolfe BE. Using cultivated microbial communities to dissect microbiome assembly: challenges, limitations, and the path ahead. mSystems. 2018;3:e00161-17.

12. Hirschberg S, Gisevius B, Duscha A, Haghikia A. Implications of diet and the gut microbiome in neuroinflammatory and neurodegenerative diseases. Int J Mol Sci. 2019;20:3109.

13. Roy Sarkar S, Banerjee S. Gut microbiota in neurodegenerative disorders. J Neuroimmunol. 2019;328:98-104.

14. Quigley EMM. Gut bacteria in health and disease. Gastroenterol Hepatol. 2013;9:560-9.

15. Zhu X, Han Y, Du J, Liu R, Jin K, Yi W. Microbiota-gut-brain axis and the central nervous system. Oncotarget. 2017;8:53829-38.

16. Lankelma JM, Nieuwdorp M, de Vos WM, Wiersinga WJ. The gut microbiota in internal medicine: implications for health and disease. Neth J Med. 2015;73:61-8.

17. Spielman LJ, Gibson DL, Klegeris A. Unhealthy gut, unhealthy brain: the role of the intestinal microbiota in neurodegenerative diseases. Neurochem Int. 2018;120:149-63.

18. Leser TD, Mølbak L. Better living through microbial action: the benefits of the mammalian gastrointestinal microbiota on the host. Environ Microbiol. 2009;11:2194-206.

19. Marques TM, Wall R, Ross RP, Fitzgerald GF, Ryan CA, Stanton C. Programming infant gut microbiota: influence of dietary and environmental factors. Curr Opin Biotechnol. 2010;21:149-56.

20. Tilocca B, Pieroni L, Soggiu A, Britti D, Bonizzi L, Roncada P, et al. Gut-brain axis and neurodegeneration: state-of-the-art of meta-omics sciences for microbiota characterization. Int J Mol Sci. 2020;21:4045.

21. Cenit MC, Sanz Y, Codoñer-Franch P. Influence of gut microbiota on neuropsychiatric disorders. World J Gastroenterol. 2017;23:5486-98.

22. Human Microbiome Project Consortium. Structure, function and diversity of the healthy human microbiome. Nature. 2012;486:207-14.

23. Li J, Jia H, Cai X, Zhong H, Feng Q, Sunagawa S, et al; MetaHIT Consortium. An integrated catalog of reference genes in the human gut microbiome. Nat Biotechnol. 2014;32:834-41.

24. Joshi D, Roy S, Banerjee S. Prebiotics: a functional food in health and disease. In: Natural products and drug discovery. An integrated approach. Elsevier; 2018. pp. 507-23.

25. Sommer F, Bäckhed F. The gut microbiota--masters of host development and physiology. Nat Rev Microbiol. 2013;11:227-38.

26. Chandra S, Alam MT, Dey J, Sasidharan BCP, Ray U, Srivastava AK, et al. Healthy gut, healthy brain: the gut microbiome in neurodegenerative disorders. Curr Top Med Chem. 2020;20:1142-53.

27. Bienenstock J, Kunze W, Forsythe P. Microbiota and the gut-brain axis. Nutr Rev. 2015;73 Suppl 1:28-31.

28. Martín R, Langella P. Emerging health concepts in the probiotics field: streamlining the definitions. Front Microbiol. 2019;10:1047.

29. Hsiao EY, McBride SW, Hsien S, Sharon G, Hyde ER, McCue T, et al. Microbiota modulate behavioral and physiological abnormalities associated with neurodevelopmental disorders. Cell. 2013;155:1451-63.

30. Sudo N, Chida Y, Aiba Y, Sonoda J, Oyama N, Yu XN, et al. Postnatal microbial colonization programs the hypothalamic-pituitary-adrenal system for stress response in mice. J Physiol. 2004;558:263-75. 
31. Farzi A, Fröhlich EE, Holzer P. Gut microbiota and the neuroendocrine system. Neurotherapeutics. 2018;15:5-22.

32. Tang F, Zhu G, Jiao Z, Ma C, Wang B. Self-reported adherence in patients with epilepsy who missed their medications and reasons for nonadherence in China. Epilepsy Behav. 2013;27:85-9.

33. Macpherson AJ, Harris NL. Interactions between commensal intestinal bacteria and the immune system. Nat Rev Immunol. 2004;4:478-85.

34. Neufeld KAM, Kang N, Bienenstock J, Foster JA. Effects of intestinal microbiota on anxiety-like behavior. Commun Integr Biol. 2011;4:492-4.

35. Sampson TR, Mazmanian SK. Control of brain development, function, and behavior by the microbiome. Cell Host Microbe. 2015;17:565-76.

36. Ridaura V, Belkaid Y. Gut microbiota: the link to your second brain. Cell. 2015;161:193-4.

37. Yano JM, Yu K, Donaldson GP, Shastri GG, Ann P, Ma L, et al. Indigenous bacteria from the gut microbiota regulate host serotonin biosynthesis. Cell. 2015;161:264-76.

38. O'Mahony SM, Clarke G, Borre YE, Dinan TG, Cryan JF. Serotonin, tryptophan metabolism and the braingut-microbiome axis. Behav Brain Res. 2015;277:32-48.

39. Luczynski P, McVey Neufeld KA, Oriach CS, Clarke G, Dinan TG, Cryan JF. Growing up in a bubble: using germ-free animals to assess the influence of the gut microbiota on brain and behavior. Int J Neuropsychopharmacol. 2016;19:pyw020.

40. Cryan JF, O'Riordan KJ, Cowan CSM, Sandhu KV, Bastiaanssen TFS, Boehme M, et al. The microbiota-gutbrain axis. Physiol Rev. 2019;99:1877-2013.

41. Fülling C, Dinan TG, Cryan JF. Gut microbe to brain signaling: what happens in vagus... Neuron. 2019;101:998-1002.

42. Ogbonnaya ES, Clarke G, Shanahan F, Dinan TG, Cryan JF, O'Leary OF. Adult hippocampal neurogenesis is regulated by the microbiome. Biol Psychiatry. 2015;78:e7-9.

43. Braniste V, Al-Asmakh M, Kowal C, Anuar F, Abbaspour A, Tóth M, et al. The gut microbiota influences blood-brain barrier permeability in mice. Sci Transl Med. 2014;6:263ra158.

44. Erny D, Hrabě de Angelis AL, Jaitin D, Wieghofer P, Staszewski O, David E, et al. Host microbiota constantly control maturation and function of microglia in the CNS. Nat Neurosci. 2015;18:965-77.

45. Cryan JF, Dinan TG. Gut microbiota: microbiota and neuroimmune signalling-Metchnikoff to microglia. Nat Rev Gastroenterol Hepatol. 2015;12:494-6.

46. Ait-Belgnaoui A, Colom A, Braniste V, Ramalho L, Marrot A, Cartier C, et al. Probiotic gut effect prevents the chronic psychological stress-induced brain activity abnormality in mice. Neurogastroenterol Motil. 2014;26:510-20.

47. Long-Smith C, O'Riordan KJ, Clarke G, Stanton C, Dinan TG, Cryan JF. Microbiota-gut-brain axis: new therapeutic opportunities. Annu Rev Pharmacol Toxicol. 2020;60:477-502.

48. Rondanelli M, Giacosa A, Faliva MA, Perna S, Allieri F, Castellazzi AM. Review on microbiota and effectiveness of probiotics use in older. World J Clin Cases. 2015;3:156-62.

49. Köhler C, Maes M, Slyepchenko A, Berk M, Solmi M, Lanctôt KL, et al. The gut-brain axis, including the microbiome, leaky gut and bacterial translocation: mechanisms and pathophysiological role in Alzheimer's disease. Curr Pharm Des. 2016;22:6152-66.

50. Obeso JA, Stamelou M, Goetz CG, Poewe W, Lang AE, Weintraub D, et al. Past, present, and future of Parkinson's disease: a special essay on the 200th Anniversary of the Shaking Palsy. Mov Disord. 2017;32:1264-1310.

51. Lanciego JL, Luquin N, Obeso JA. Functional neuroanatomy of the basal ganglia. Cold Spring Harb Perspect Med. 2012;2:a009621. 
52. Blesa J, Lanciego JL, Obeso JA. Editorial: Parkinson's disease: cell vulnerability and disease progression. Front Neuroanat. 2015;9:125.

53. Nair AT, Ramachandran V, Joghee NM, Antony S, Ramalingam G. Gut microbiota dysfunction as reliable non-invasive early diagnostic biomarkers in the pathophysiology of Parkinson's disease: a critical review. J Neurogastroenterol Motil. 2018;24:30-42.

54. Blauwendraat C, Heilbron K, Vallerga CL, Bandres-Ciga S, von Coelln R, Pihlstrøm L, et al; International Parkinson's Disease Genomics Consortium (IPDGC). Parkinson's disease age at onset genome-wide association study: defining heritability, genetic loci, and $\alpha$-synuclein mechanisms. Mov Disord. 2019;34:866-75.

55. Franco R, Navarro G, Martínez-Pinilla E. Lessons on differential neuronal-death-vulnerability from familial cases of Parkinson's and Alzheimer's diseases. Int J Mol Sci. 2019;20:3297

56. Franco R, Rivas-Santisteban R, Reyes-Resina I, Navarro G, Martínez-Pinilla E. Microbiota and other preventive strategies and non-genetic risk factors in Parkinson's disease. Front Aging Neurosci. 2020;12:12.

57. Li Y, Cookson MR. Proteomics; applications in familial Parkinson's disease. J Neurochem. 2019;151:446-58.

58. Hornykiewicz 0 . The discovery of dopamine deficiency in the parkinsonian brain. J Neural Transm Suppl. 2006;70:9-15.

59. Birkmayer W, Hornykiewicz O. Der $L$-Dioxyphenylalanin (= $L$-DOPA)-Effekt beim Parkinson-Syndrom des Menschen: zur Pathogenese und Behandlung der Parkinson-Akinese. Arch für Psychiatr und Nervenkrankheiten. 1962;203:560-74. German.

60. Birkmayer W, Hornykiewicz O. Weitere experimentelle Untersuchungen über $L$-DOPA beim ParkinsonSyndrom und Reserpin-Parkinsonismus. Arch für Psychiatr und Nervenkrankheiten. 1964;206:36781. German.

61. Cacabelos R. Parkinson's disease: from pathogenesis to pharmacogenomics. Int J Mol Sci. 2017;18:551.

62. Armstrong MJ, Okun MS. Diagnosis and treatment of Parkinson disease: a review. JAMA. 2020;323: 548-60.

63. Guridi J, Rodriguez-Rojas R, Carmona-Abellán M, Parras O, Becerra V, Lanciego JL. History and the future challenges of the subthalamic nucleus as surgical target: review article. Mov Disord. 2018;33:1540-50.

64. Boertien JM, Pereira PAB, Aho VTE, Scheperjans F. Increasing comparability and utility of gut microbiome studies in Parkinson's disease: a systematic review. J Parkinsons Dis. 2019;9:S297-312.

65. Houser MC, Tansey MG. The gut-brain axis: is intestinal inflammation a silent driver of Parkinson's disease pathogenesis? NPJ Parkinsons Dis. 2017;3:3.

66. Parashar A, Udayabanu M. Gut microbiota: implications in Parkinson's disease. Parkinsonism Relat Disord. 2017;38:1-7.

67. Braak H, de Vos RAI, Bohl J, Del Tredici K. Gastric $\alpha$-synuclein immunoreactive inclusions in Meissner's and Auerbach's plexuses in cases staged for Parkinson's disease-related brain pathology. Neurosci Lett. 2006;396:67-72.

68. Svensson E, Horváth-Puhó E, Thomsen RW, Djurhuus JC, Pedersen L, Borghammer P, et al. Vagotomy and subsequent risk of Parkinson's disease. Ann Neurol. 2015;78:522-9.

69. Scheperjans F, Aho V, Pereira PAB, Koskinen K, Paulin L, Pekkonen E, et al. Gut microbiota are related to Parkinson's disease and clinical phenotype. Mov Disord. 2015;30:350-8.

70. Lubomski M, Tan AH, Lim SY, Holmes AJ, Davis RL, Sue CM. Parkinson's disease and the gastrointestinal microbiome. J Neurol. 2020;267:2507-23. 
71. Guo S, Al-Sadi R, Said HM, Ma TY. Lipopolysaccharide causes an increase in intestinal tight junction permeability in vitro and in vivo by inducing enterocyte membrane expression and localization of TLR-4 and CD14. Am J Pathol. 2013;182:375-87.

72. Song S, Liu J, Zhang F, Hong JS. Norepinephrine depleting toxin DSP-4 and LPS alter gut microbiota and induce neurotoxicity in $\alpha$-synuclein mutant mice. Sci Rep. 2020;10:15054.

73. Singh NK, Banerjee BD, Bala K, Chhillar M, Chhillar N. Gene-gene and gene-environment interaction on the risk of Parkinson's disease. Curr Aging Sci. 2014;7:101-9.

74. Keshavarzian A, Green SJ, Engen PA, Voigt RM, Naqib A, Forsyth CB, et al. Colonic bacterial composition in Parkinson's disease. Mov Disord. 2015;30:1351-60.

75. Pal GD, Shaikh M, Forsyth CB, Ouyang B, Keshavarzian A, Shannon KM. Abnormal lipopolysaccharide binding protein as marker of gastrointestinal inflammation in Parkinson disease. Front Neurosci. 2015;9:306.

76. Milan Manani S, Virzì GM, Giuliani A, Baretta M, Corradi V, De Cal M, et al. Lipopolysaccharide evaluation in peritoneal dialysis patients with peritonitis. Blood Purif. 2020;49:434-9.

77. Del Tredici K, Braak H. A not entirely benign procedure: progression of Parkinson's disease. Acta Neuropathol. 2008;115:379-84.

78. Mukherjee A, Biswas A, Das SK. Gut dysfunction in Parkinson's disease. World J Gastroenterol. 2016;22:5742-52.

79. Felice VD, Quigley EM, Sullivan AM, O'Keeffe GW, O'Mahony SM. Microbiota-gut-brain signalling in Parkinson's disease: implications for non-motor symptoms. Parkinsonism Relat Disord. 2016;27:1-8.

80. Holmqvist S, Chutna O, Bousset L, Aldrin-Kirk P, Li W, Björklund T, et al. Direct evidence of Parkinson pathology spread from the gastrointestinal tract to the brain in rats. Acta Neuropathol. 2014;128:805-20.

81. Uemura N, Yagi H, Uemura MT, Hatanaka Y, Yamakado H, Takahashi R. Inoculation of $\alpha$-synuclein preformed fibrils into the mouse gastrointestinal tract induces Lewy body-like aggregates in the brainstem via the vagus nerve. Mol Neurodegener. 2018;13:21.

82. Sampson TR, Debelius JW, Thron T, Janssen S, Shastri GG, Ilhan ZE, et al. Gut microbiota regulate motor deficits and neuroinflammation in a model of Parkinson's disease. Cell. 2016;167:1469-80.e12.

83. Shen X, Yang H, Wu Y, Zhang D, Jiang H. Meta-analysis: association of Helicobacter pylori infection with Parkinson's diseases. Helicobacter. 2017;22:e12398.

84. Fasano A, Bove F, Gabrielli M, Petracca M, Zocco MA, Ragazzoni E, et al. The role of small intestinal bacterial overgrowth in Parkinson's disease. Mov Disord. 2013;28:1241-9.

85. Tan AH, Mahadeva S, Thalha AM, Gibson PR, Kiew CK, Yeat CM, et al. Small intestinal bacterial overgrowth in Parkinson's disease. Parkinsonism Relat Disord. 2014;20:535-40.

86. Çamcı G, Oğuz S. Association between Parkinson's disease and Helicobacter pylori. J Clin Neurol. 2016;12:147-50.

87. Dardiotis E, Tsouris Z, Mentis AFA, Siokas V, Michalopoulou A, Sokratous M, et al. H. pylori and Parkinson's disease: meta-analyses including clinical severity. Clin Neurol Neurosurg. 2018;175:16-24.

88. Anderson G, Seo M, Berk M, Carvalho AF, Maes M. Gut permeability and microbiota in Parkinson's disease: role of depression, tryptophan catabolites, oxidative and nitrosative stress and melatonergic pathways. Curr Pharm Des. 2016;22:6142-51.

89. Gazerani P. Probiotics for Parkinson's disease. Int J Mol Sci. 2019;20:4121.

90. Cassani E, Privitera G, Pezzoli G, Pusani C, Madio C, Iorio L, et al. Use of probiotics for the treatment of constipation in Parkinson's disease patients. Minerva Gastroenterol Dietol. 2011;57:117-21.

91. Georgescu D, Ancusa OE, Georgescu LA, Ionita I, Reisz D. Nonmotor gastrointestinal disorders in older patients with Parkinson's disease: is there hope? Clin Interv Aging. 2016;11:1601-8. 
92. Tamtaji OR, Taghizadeh M, Daneshvar Kakhaki R, Kouchaki E, Bahmani F, Borzabadi S, et al. Clinical and metabolic response to probiotic administration in people with Parkinson's disease: a randomized, double-blind, placebo-controlled trial. Clin Nutr. 2019;38:1031-5.

93. Srivastav S, Neupane S, Bhurtel S, Katila N, Maharjan S, Choi H, et al. Probiotics mixture increases butyrate, and subsequently rescues the nigral dopaminergic neurons from MPTP and rotenone-induced neurotoxicity. J Nutr Biochem. 2019;69:73-86.

94. Surwase SN, Jadhav JP. Bioconversion of $L$-tyrosine to $L$-DOPA by a novel bacterium Bacillus sp. JPJ. Amino Acids. 2011;41:495-506.

95. van Kessel SP, Frye AK, El-Gendy AO, Castejon M, Keshavarzian A, van Dijk G, et al. Gut bacterial tyrosine decarboxylases restrict levels of levodopa in the treatment of Parkinson's disease. Nat Commun. 2019;10:310.

96. Barichella M, Pacchetti C, Bolliri C, Cassani E, Iorio L, Pusani C, et al. Probiotics and prebiotic fiber for constipation associated with Parkinson disease: an RCT. Neurology. 2016;87:1274-80.

97. Gentile F, Doneddu PE, Riva N, Nobile-Orazio E, Quattrini A. Diet, microbiota and brain health: unraveling the network intersecting metabolism and neurodegeneration. Int J Mol Sci. 2020;21:7471.

98. Gubert C, Kong G, Renoir T, Hannan AJ. Exercise, diet and stress as modulators of gut microbiota: implications for neurodegenerative diseases. Neurobiol Dis. 2020;134:104621.

99. Chen C, Zhang BB, Hu AL, Li H, Liu J, Zhang F. Protective role of cinnabar and realgar in Hua-FengDan against LPS plus rotenone-induced neurotoxicity and disturbance of gut microbiota in rats. J Ethnopharmacol. 2020;247:112299.

100. Hu AL, Song S, Li Y, Xu SF, Zhang F, Li C, et al. Mercury sulfide-containing Hua-Feng-Dan and 70W (Rannasangpei) protect against LPS plus MPTP-induced neurotoxicity and disturbance of gut microbiota in mice. J Ethnopharmacol. 2020;254:112674.

101. Huang H, Xu H, Luo Q, He J, Li M, Chen H, et al. Fecal microbiota transplantation to treat Parkinson's disease with constipation: a case report. Medicine (Baltimore). 2019;98:e16163.

102. Liu J, Xu F, Nie Z, Shao L. Gut microbiota approach-a new strategy to treat Parkinson's disease. Front Cell Infect Microbiol. 2020;10:570658.

103. Tremlett H, Bauer KC, Appel-Cresswell S, Finlay BB, Waubant E. The gut microbiome in human neurological disease: a review. Ann Neurol. 2017;81:369-82.

104. Khoruts A, Hoffmann DE, Palumbo FB. The impact of regulatory policies on the future of fecal microbiota transplantation. J Law Med Ethics. 2019;47:482-504.

105. 2020 Alzheimer's disease facts and figures. Alzheimers Dement. 16:391-460.

106. Möller HJ, Graeber MB. The case described by Alois Alzheimer in 1911. Historical and conceptual perspectives based on the clinical record and neurohistological sections. Eur Arch Psychiatry Clin Neurosci. 1998;248:111-22.

107. Serrano-Pozo A, Frosch MP, Masliah E, Hyman BT. Neuropathological alterations in Alzheimer disease. Cold Spring Harb Perspect Med 2011;1:a006189.

108. Nussbaum RL, Ellis CE. Alzheimer's disease and Parkinson's disease. N Engl J Med. 2003;348:1356-64.

109. Ganguly G, Chakrabarti S, Chatterjee U, Saso L. Proteinopathy, oxidative stress and mitochondrial dysfunction: cross talk in Alzheimer's disease and Parkinson's disease. Drug Des Devel Ther. 2017;11:797-810.

110. DeTure MA, Dickson DW. The neuropathological diagnosis of Alzheimer's disease. Mol Neurodegener. 2019;14:32.

111. Braak H, Braak E. Staging of Alzheimer's disease-related neurofibrillary changes. Neurobiol Aging. 1995;16:271-8. 
112. Sweeney MD, Sagare AP, Zlokovic BV. Blood-brain barrier breakdown in Alzheimer disease and other neurodegenerative disorders. Nat Rev Neurol. 2018;14:133-50.

113. Nelson AR, Sweeney MD, Sagare AP, Zlokovic BV. Neurovascular dysfunction and neurodegeneration in dementia and Alzheimer's disease. Biochim Biophys Acta. 2016;1862:887-900.

114. Boscher E, Husson T, Quenez O, Laquerrière A, Marguet F, Cassinari K, et al. Copy number variants in miR-138 as a potential risk factor for early-onset Alzheimer's disease. J Alzheimers Dis. 2019;68:1243-55.

115. Ramirez Aguilar L, Acosta-Uribe J, Giraldo MM, Moreno S, Baena A, Alzate D, et al. Genetic origin of a large family with a novel PSEN1 mutation (Ile416Thr). Alzheimers Dement. 2019;15:709-19.

116. Cummings JL, Tong G, Ballard C. Treatment combinations for Alzheimer's disease: current and future pharmacotherapy options. J Alzheimers Dis. 2019;67:779-94.

117. Bachurin SO, Gavrilova SI, Samsonova A, Barreto GE, Aliev G. Mild cognitive impairment due to Alzheimer disease: contemporary approaches to diagnostics and pharmacological intervention. Pharmacol Res. 2018;129:216-26.

118. van Dyck CH. Anti-amyloid- $\beta$ monoclonal antibodies for Alzheimer's disease: pitfalls and promise. Biol Psychiatry. 2018;83:311-9.

119. Wischik CM, Harrington CR, Storey JMD. Tau-aggregation inhibitor therapy for Alzheimer's disease. Biochem Pharmacol. 2014;88:529-39.

120. Bruce-Keller AJ, Salbaum JM, Luo M, Blanchard E 4th, Taylor CM, Welsh DA, et al. Obese-type gut microbiota induce neurobehavioral changes in the absence of obesity. Biol Psychiatry. 2015;77:607-15.

121. Zhan G, Yang N, Li S, Huang N, Fang X, Zhang J, et al. Abnormal gut microbiota composition contributes to cognitive dysfunction in SAMP8 mice. Aging (Albany NY). 2018;10:1257-67.

122. Miró Ll, Moretó M, Amat C, Polo J, Pérez-Bosque A. Aging effects on gut microbiota in SAMP8 mice. MDPI. 2020;61:25.

123. Vogt NM, Kerby RL, Dill-McFarland KA, Harding SJ, Merluzzi AP, Johnson SC, et al. Gut microbiome alterations in Alzheimer's disease. Sci Rep. 2017;7:13537.

124. Zhuang ZQ, Shen LL, Li WW, Fu X, Zeng F, Gui L, et al. Gut microbiota is altered in patients with Alzheimer's disease. J Alzheimers Dis. 2018;63:1337-46.

125. Park AM, Omura S, Fujita M, Sato F, Tsunoda I. Helicobacter pylori and gut microbiota in multiple sclerosis versus Alzheimer's disease: 10 pitfalls of microbiome studies. Clin Exp Neuroimmunol. 2017;8:215-32.

126. Roubaud-Baudron C, Krolak-Salmon P, Quadrio I, Mégraud F, Salles N. Impact of chronic Helicobacter pylori infection on Alzheimer's disease: preliminary results. Neurobiol Aging. 2012;33:1009.e11-9.

127. Cattaneo A, Cattane N, Galluzzi S, Provasi S, Lopizzo N, Festari C, et al. Association of brain amyloidosis with pro-inflammatory gut bacterial taxa and peripheral inflammation markers in cognitively impaired elderly. Neurobiol Aging. 2017;49:60-8.

128. Sobol CV. Role of microbiota in neurodegenerative diseases. Russ J Dev Biol. 2018;49:297-313.

129. Zhao Y, Dua P, Lukiw WJ. Microbial sources of amyloid and relevance to amyloidogenesis and Alzheimer's disease (AD). J Alzheimers Dis Parkinsonism. 2015;5:177.

130. Hill JM, Lukiw WJ. Microbial-generated amyloids and Alzheimer's disease (AD). Front Aging Neurosci. 2015;7:9.

131. Bu XL, Xiang Y, Jin WS, Wang J, Shen LL, Huang ZL, et al. Blood-derived amyloid- $\beta$ protein induces Alzheimer's disease pathologies. Mol Psychiatry. 2018;23:1948-56.

132. Asti A, Gioglio L. Can a bacterial endotoxin be a key factor in the kinetics of amyloid fibril formation? J Alzheimers Dis. 2014;39:169-79.

133. Harach T, Marungruang N, Duthilleul N, Cheatham V, Mc Coy KD, Frisoni G, et al. Reduction of Abeta amyloid pathology in APPPS1 transgenic mice in the absence of gut microbiota. Sci Rep. 2017;7:41802. 
134. Minter MR, Zhang C, Leone V, Ringus DL, Zhang X, Oyler-Castrillo P, et al. Antibiotic-induced perturbations in gut microbial diversity influences neuro-inflammation and amyloidosis in a murine model of Alzheimer's disease. Sci Rep. 2016;6:30028.

135. Kobayashi Y, Sugahara H, Shimada K, Mitsuyama E, Kuhara T, Yasuoka A, et al. Therapeutic potential of Bifidobacterium breve strain A1 for preventing cognitive impairment in Alzheimer's disease. Sci Rep. 2017;7:13510.

136. Yang X, Yu D, Xue L, Li H, Du J. Probiotics modulate the microbiota-gut-brain axis and improve memory deficits in aged SAMP8 mice. Acta Pharm Sin B. 2020;10:475-87.

137. Yamamoto K, Kushida M, Tsuduki T. The effect of dietary lipid on gut microbiota in a senescenceaccelerated prone mouse model (SAMP8). Biogerontology. 2018;19:367-83.

138. Wang J, Lei X, Xie Z, Zhang X, Cheng X, Zhou W, et al. CA-30, an oligosaccharide fraction derived from Liuwei Dihuang decoction, ameliorates cognitive deterioration via the intestinal microbiome in the senescence-accelerated mouse prone 8 strain. Aging (Albany NY). 2019;11:3463-86.

139. Bonfili L, Cecarini V, Cuccioloni M, Angeletti M, Berardi S, Scarpona S, et al. SLAB51 probiotic formulation activates SIRT1 pathway promoting antioxidant and neuroprotective effects in an AD mouse model. Mol Neurobiol. 2018;55:7987-8000.

140. Azm SAN, Djazayeri A, Safa M, Azami K, Ahmadvand B, Sabbaghziarani F, et al. Lactobacilli and bifidobacteria ameliorate memory and learning deficits and oxidative stress in $\beta$-amyloid (1-42) injected rats. Appl Physiol Nutr Metab. 2018;43:718-26.

141. Nimgampalle M, Yellamma K. Anti-Alzheimer properties of probiotic, Lactobacillus plantarum MTCC 1325 in Alzheimer's disease induced albino rats. J Clin Diagn Res. 2017;11:KC01-5.

142. Distrutti E, O'Reilly JA, McDonald C, Cipriani S, Renga B, Lynch MA, et al. Modulation of intestinal microbiota by the probiotic VSL\#3 resets brain gene expression and ameliorates the age-related deficit in LTP. PLoS One. 2014;9:e106503.

143. Yen $\mathrm{CH}$, Wang $\mathrm{CH}, \mathrm{Wu} \mathrm{WT}$, Chen HL. Fructo-oligosaccharide improved brain $\beta$-amyloid, $\beta$-secretase, cognitive function, and plasma antioxidant levels in $D$-galactose-treated Balb/cJ mice. Nutr Neurosci. 2017;20:228-37.

144. Ono K, Hirohata M, Yamada M. Ferulic acid destabilizes preformed $\beta$-amyloid fibrils in vitro. Biochem Biophys Res Commun. 2005;336:444-9.

145. Sun M, Wu W, Chen L, Yang W, Huang X, Ma C, et al. Microbiota-derived short-chain fatty acids promote Th1 cell IL-10 production to maintain intestinal homeostasis. Nat Commun. 2018;9:3555.

146. Han D, Li Z, Liu T, Yang N, Li Y, He J, et al. Prebiotics regulation of intestinal microbiota attenuates cognitive dysfunction induced by surgery stimulation in APP/PS1 mice. Aging Dis. 2020;11:1029-45.

147. Akbari E, Asemi Z, Daneshvar Kakhaki R, Bahmani F, Kouchaki E, Tamtaji OR, et al. Effect of probiotic supplementation on cognitive function and metabolic status in Alzheimer's disease: a randomized, double-blind and controlled trial. Front Aging Neurosci. 2016;8:256.

148. Agahi A, Hamidi GA, Daneshvar R, Hamdieh M, Soheili M, Alinaghipour A, et al. Does severity of Alzheimer's disease contribute to its responsiveness to modifying gut microbiota? A double blind clinical trial. Front Neurol. 2018;9:662.

149. Tamtaji OR, Heidari-soureshjani R, Mirhosseini N, Kouchaki E, Bahmani F, Aghadavod E, et al. Probiotic and selenium co-supplementation, and the effects on clinical, metabolic and genetic status in Alzheimer's disease: a randomized, double-blind, controlled trial. Clin Nutr. 2019;38:2569-75.

150. Ton AMM, Campagnaro BP, Alves GA, Aires R, Côco LZ, Arpini CM, et al. Oxidative stress and dementia in Alzheimer's patients: effects of synbiotic supplementation. Oxid Med Cell Longev. 2020:2638703.

151. Vendrik KEW, Ooijevaar RE, de Jong PRC, Laman JD, van Oosten BW, van Hilten JJ, et al. Fecal microbiota transplantation in neurological disorders. Front Cell Infect Microbiol. 2020;10:98. 
152. Sun J, Xu J, Ling Y, Wang F, Gong T, Yang C, et al. Fecal microbiota transplantation alleviated Alzheimer's disease-like pathogenesis in APP/PS1 transgenic mice. Transl Psychiatry. 2019;9:189.

153. Holsinger RMD, Elangovan S. Neuroprotective effects of fecal microbiota transplantation in a mouse model of Alzheimer's disease. Alzheimers Dement. 2020;16:e046523.

154. Hazan S. Rapid improvement in Alzheimer's disease symptoms following fecal microbiota transplantation: a case report. J Int Med Res. 2020;48:300060520925930.

155. Walker FO. Huntington's disease. Lancet. 2007;369:218-28.

156. Andrew SE, Goldberg YP, Kremer B, Telenius H, Theilmann J, Adam S, et al. The relationship between trinucleotide (CAG) repeat length and clinical features of Huntington's disease. Nat Genet. 1993;4:398-403.

157. Ross SE, Johnson KB, Siek KA, Gordon JS, Khan DU, Haverhals LM. Two complementary personal medication management applications developed on a common platform: case report. J Med Internet Res. 2011;13:e45.

158. Tabrizi SJ, Scahill RI, Durr A, Roos RA, Leavitt BR, Jones R, et al. Biological and clinical changes in premanifest and early stage Huntington's disease in the TRACK-HD study: the 12-month longitudinal analysis. Lancet Neurol. 2011;10:31-42.

159. Cattaneo E, Zuccato C, Tartari M. Normal huntingtin function: an alternative approach to Huntington's disease. Nat Rev Neurosci. 2005;6:919-30.

160. Labbadia J, Morimoto RI. Huntington's disease: underlying molecular mechanisms and emerging concepts. Trends Biochem Sci. 2013;38:378-85.

161. Wolf RC, Thomann PA, Thomann AK, Vasic N, Wolf ND, Landwehrmeyer GB, et al. Brain structure in preclinical Huntington's disease: a multi-method approach. Neurodegener Dis. 2013;12:13-22.

162. McColgan P, Tabrizi SJ. Huntington's disease: a clinical review. Eur J Neurol. 2018;25:24-34.

163. Ross CA, Tabrizi SJ. Huntington's disease: from molecular pathogenesis to clinical treatment. Lancet Neurol. 2011;10:83-98.

164. Roze E, Saudou F, Caboche J. Pathophysiology of Huntington's disease: from huntingtin functions to potential treatments. Curr Opin Neurol. 2008;21:497-503.

165. Frank S. Treatment of Huntington's disease. Neurotherapeutics. 2014;11:153-60.

166. Creus-Muncunill J, Guisado-Corcoll A, Venturi V, Pantano L, Escaramís G, García de Herreros M, et al. Huntington's disease brain-derived small RNAs recapitulate associated neuropathology in mice. Acta Neuropathol. 2021;141:565-84.

167. van der Burg JMM, Winqvist A, Aziz NA, Maat-Schieman MLC, Roos RAC, Bates GP, et al. Gastrointestinal dysfunction contributes to weight loss in Huntington's disease mice. Neurobiol Dis. 2011;44:1-8.

168. van der Burg JMM, Gardiner SL, Ludolph AC, Landwehrmeyer GB, Roos RAC, Aziz NA. Body weight is a robust predictor of clinical progression in Huntington disease. Ann Neurol. 2017;82:479-83.

169. Verwaest KA, Vu TN, Laukens K, Clemens LE, Nguyen HP, Van Gasse B, et al. 1H NMR based metabolomics of CSF and blood serum: a metabolic profile for a transgenic rat model of Huntington disease. Biochim Biophys Acta. 2011;1812:1371-9.

170. Kong G, Cao KAL, Judd LM, Li S, Renoir T, Hannan AJ. Microbiome profiling reveals gut dysbiosis in a transgenic mouse model of Huntington's disease. Neurobiol Dis. 2020;135:104268.

171. Stan TL, Soylu-Kucharz R, Burleigh S, Prykhodko O, Cao L, Franke N, etal. Increased intestinal permeability and gut dysbiosis in the R6/2 mouse model of Huntington's disease. Sci Rep. 2020;10:18270.

172. Radulescu CI, Garcia-Miralles M, Sidik H, Bardile CF, Yusof NABM, Lee HU, et al. Manipulation of microbiota reveals altered callosal myelination and white matter plasticity in a model of Huntington disease. Neurobiol Dis. 2019;127:65-75. 
173. Wasser CI, Mercieca EC, Kong G, Hannan AJ, McKeown SJ, Glikmann-Johnston Y, et al. Gut dysbiosis in Huntington's disease: associations among gut microbiota, cognitive performance and clinical outcomes. Brain Commun. 2020;2:fcaa110.

174. Rea K, Dinan TG, Cryan JF. Gut microbiota: a perspective for psychiatrists. Neuropsychobiology. 2020;79:50-62.

175. Kim YK, Shin C. The microbiota-gut-brain axis in neuropsychiatric disorders: pathophysiological mechanisms and novel treatments. Curr Neuropharmacol. 2018;16:559-73.

176. Biagi E, Nylund L, Candela M, Ostan R, Bucci L, Pini E, et al. Through ageing, and beyond: gut microbiota and inflammatory status in seniors and centenarians. PLoS One. 2010;5:e10667.

177. Biagi E, Rampelli S, Turroni S, Quercia S, Candela M, Brigidi P. The gut microbiota of centenarians: signatures of longevity in the gut microbiota profile. Mech Ageing Dev. 2017;165:180-4.

178. Odamaki T, Kato K, Sugahara H, Hashikura N, Takahashi S, Xiao JZ, et al. Age-related changes in gut microbiota composition from newborn to centenarian: a cross-sectional study. BMC Microbiol. 2016;16:90.

179. Ma Q Xing C, Long W, Wang HY, Liu Q Wang RF. Impact of microbiota on central nervous system and neurological diseases: the gut-brain axis. J Neuroinflammation. 2019;16:53.

180. Arora K, Green M, Prakash S. The microbiome and Alzheimer's disease: potential and limitations of prebiotic, synbiotic, and probiotic formulations. Front Bioeng Biotechnol. 2020;8:537847. 